\title{
Analysis of the Problems of Chinese Education in Rural Schools and Its Countermeasures
}

\author{
Guo Taoying, Xiao Jiugen* \\ Research Center of Language and language Life, Jiangxi Normal University, Nanchang, China \\ Email address: \\ 1747397739@qq.com (Guo Taoying),jxsdxjg666666@sina.com (Xiao Jiugen) \\ * Corresponding author
}

To cite this article:

Guo Taoying, Xiao Jiugen. Analysis of the Problems of Chinese Education in Rural Schools and Its Countermeasures. Science Innovation. Vol. 8, No. 4, 2020, pp. 109-113. doi: 10.11648/j.si.20200804.15

Received: June 19, 2020; Accepted: July 31, 2020; Published: August 10, 2020

\begin{abstract}
Since the new era, China's basic education has developed vigorously, which has provided a large number of talents for socialist construction and institutions of higher learning. However, it should also be clearly seen that there are still some problems that cannot be ignored in China's rural education, especially Chinese education, due to various reasons, which to some extent restrict the development of rural education. As is known to all, Chinese education is the foundation of education in other subjects. Only by improving the quality of Chinese education can the overall quality of education in rural schools be improved. In recent years, the main factors affecting the quality of Chinese education in rural schools are as follows: first, affected by the investment of funds, the teaching facilities in rural schools are very poor, and the teaching staff is also very weak; Second, due to information occlusion, teachers' educational concept is relatively backward, and their teaching language is dialectal; Third, some teachers do not grasp the curriculum standards in place, follow the old teaching plan, no sense of innovation. To fundamentally reverse this situation, we must increase the investment of educational funds, solve the problem of teachers' salary, take effective measures to improve their professional quality and teaching level, and urge them to renew their ideas and forge ahead. In this way, the improvement of the quality of Chinese education in rural schools is just around the corner.
\end{abstract}

Keywords: Rural Schools, Chinese Education, Teaching Problems, Countermeasures

\section{农村学校语文教育问题分析及其对策}

\author{
郭桃英, 肖九根 ${ }^{*}$ \\ 江西师范大学语言与语言生活中心, 南昌, 中国 \\ 邮箱 \\ 1747397739@qq.com（郭桃英）, jxsdxjg666666@sina.com（肖九根）
}

摘要: 新时期以来, 我国的基础教育事业得到了蓬勃的发展, 为社会主义建设和高等院校输送了大批人才。不过, 也 应清楚地看到, 由于各种原因我国的农村教育尤其是语文教育仍然存在一些不容忽视的问题, 这在一定程度上制约了 农村教育事业的发展。众所周知, 语文教育是其它学科教育的基础, 只有提高了语文教育质量, 才能提高农村学校的 整体教育质量。近些年来, 影响农村学校语文教育质量主要存在以下因素：一是受经费投入的影响，农村学校教学设 施十分贵乏, 而且师资力量也很薄弱; 二是由于信息闭塞, 教师的教育观念相对滞后, 其教学用语方言化; 三是有些 教师对课标把握不到位, 沿袭老教案, 毫无创新意识。要从根本上扭转这一局面, 就要加大教育经费的投入, 切实解 决教师待遇问题, 并采取有效措施提高他们的业务素质和教学水平, 促其更新观念, 开拓进取。诚如是, 农村学校语 文教育质量的提高便指日可待。 
关键词: 农村学校, 语文教育, 教学问题, 解决措施

\section{1. 引言}

农村教育问题历来就是教育界关注的重大问题, 在社 会快速发展的今天就更是如此。部分农村地区由于地理位 置偏僻, 在教育方面投入不够, 既是到了今天, 其对教育 重视的程度也还远远不够。究其根本原因, 最主要的是农 村地区经济落后, 致使教育资源不足, 教育质量不高, 从 而导致农村地区教育存在很多问题。例如，农村地区语文 教育就存在诸多问题, 严重影响了农村地区语文教学质 量。语文教育是基础, 只有语文教育水平上去了, 整体教 育水平才会得到提高。所以, 要想解决农村地区的教育问 题, 首先就得找出农村地区语文教育中的问题。论文以农 村地区语文教育为主题, 分析农村语文教育存在的问题, 继而提出相应的解决措施。只有找出问题, 制定解决问题 的措施，农村地区语文教育质量才有望提高。

目前, 农村教育问题已经引起了专家学者的重视, 他 们主要从以下方面讨论了其所存在的问题: 一是教育经费 的投入问题。例如, 张静（2015）[1]、李云洲（2017） [2] 以及李娜 (2020) [3]等都提出了农村教育投入不足以致出 现的教学设施陈旧、师资力量薄弱等问题。李云洲谈起这 一问题时指出: “很多农村小学由于自然环境、地理环境 以及经济条件的原因,导致教育事业落后。因为教学条件 的不允许,孩子们能看到的课外阅读资料又特别少,他们的 视野仅仅局限于大山, 对于大山以外的事物一无所知....... 经济条件与办学条件的落后等原因,严重阻碍了山区教育 事业的发展。”[2]二是农村实行素质教育效果不佳的问题。 今天不少农村学校仍然实行应试教育, 唯分数至上, 不注 重学生全面发展, 这些问题也在一定程度上阻碍了学生语 文素养的提高。例如, 刘建尔 (2012) [4]和陈强 (2016) [5]都认为, 目前农村学校并未按素质教育的标准培养学 生, 其教学观念还相对落后。三是农村留守儿童多的问题。 农村留守儿童是学校教育多年来存在的问题, 这严重地影 响了农村教育的教学效果, 也使语文教育质量受到了一定 的影响。张静（2015）[1]就指出农村家长（实际上是爷爷 奶奶) 素质不高, 对孩子存在重智轻德、本末倒置的现象。 李松（2019）[6]和李娜（2020）[3]研究表明由于农村留 守儿童多, 许多孩子缺乏学习的热情。

关于如何提高农村教育质量的问题, 专家学者针对存 在的问题也开出了药方: 一是要切实增加农村教育经费的 投入。要提高农村教育质量, 增加经费的投入是必不可少 的。张静（2015）指出: “针对教育财政资金问题,建议政府 在合理的范围内, 尽可能多的将经费也能投入到农村学校, 使农村学校的硬件教育设施更加完善,为农村学生能提供 最基础的学习环境。”[1]二是教师教学的方式方法以及观念 要转变。学校教育, 教师是关键, 教师的水平很大程度上 决定了教学质量的好坏。李爱丰 (2011) 认为在语文教学 中要培养学生的问题意识。[7]李金云、高玉霞 (2017) 主 张应大力“提升农村教师教科书素养,关注教科书分析方法 和评判意识,助力教师教科书研究的专业性”。

\section{2. 农村地区语文教育存在的问题}

\section{1. 基础设施匮乏}

进入 21 世纪以来, 由于国家越来越重视教育, 使得教 育事业得到了快速发展, 尤其是城镇教育。无庸讳言, 农 村教育仍然处于相对落后状态, 其中基础设施匮乏是主要 原因之一。语文教育中, 如果还是处在一支粉笔、一块黑 板的教学模式下, 教学效果就会大打折扣, 尤其在当今提 倡快乐学习的时代。[1]俗话说: “巧妇难为无米之炊。” 这就特别强调了工具的重要性。在农村中小学, 不少学校 由于多媒体设施匮乏, 课文中的情境和优美画面仅能通过 语言文字来领悟, 这就不利于学生思维的多维发展, 也不 利于学生智力的开发, 更有碍于学生视野的拓展。不少学 生对语文的认知, 就仅局限于课本, 这就大大降低了他们 学习语文的兴趣。而城镇教育, 由于具备了完备的教学设 备, 学生所接受的语文教育全面而深入, 视野十分开阔, 这是农村教育与城镇教育产生大的差别原因之一。

再者, 即使有的农村学校配备了多媒体教学设施, 但 是由于部分教师不能或不善于使用新科技, 结果那些多媒 体也就成了摆设; 或者部分教师的教学观念还未更新, 依 旧沉浸在旧的教学模式中, 压根儿就不想使用多媒体教 学。[9]在他们看来, 多媒体完全是多余的, 即使不用它, 他们同样能将语文课讲得生动、有趣。这样, 有些拥有多 媒体设备的学校, 也未能充分地利用它, 语文课还是仅限 于课本中, 其教学质量也就难以有一个大的提高。农村学 校图书馆未能得到充分利用也是一个重要原因。有的学校 虽然配备了图书馆, 但是藏书极少, 而且其书籍也没有根 据社会发展的要求及时更新, 更没有组织学生做书籍借阅 这一工作, 图书馆实际上也成了一个摆设。另外, 不少村 小，连图书馆都没有。

\section{2. 师资力量薄弱}

农村地理位置较为偏僻，经济条件也相对落后，很多 优秀教师都愿去城里发展, 其工资待遇、工作条件、生活 环境、个人前途等方面, 都是农村学校无法比拟的。再者, 即使有的农村学校有很优秀的教师, 也会被城镇学校以更 高的薪酬或更好的福利而“挖”走。这样, 就使本来师资薄 弱的农村学校雪上加霜。不仅如此, 部分农村学校还有一 些教师没有教师资格证, 他们仅有初、高中或中专学历, 没有受过专业训练, 教学水平较低, 因此其教学质量也就 可想而知了。[2]与此同时, 部分农村地区还存在着教师老 龄化的问题。很多年轻的教师不愿意留在农村, 这就导致 了农村教师的年龄普遍较大。而年龄大的教师工作热情以 及思想观念赶不上年轻教师, 这也是农村地区教学质量难 以提高的原因之一。此外, 有些农村学校出现教师人数不 够的容况, 以致存在不少教师身兼数职的现象。[8,3]众所 周知, 语文教育是一项巨大的工程, 涉及的知识面十分地 
广, 教师要想教好语文课, 课前必须认真备好课, 准备好 各种教学资料, 而身兼数职的教师是没有多少时间和精力 去认真备课的, 这必然会影响课堂教学效果。再者, 有些 学校缺少初中教师, 则从小学调老师, 而这些老师的教学 经验仅限于小学, 又怎能教好初中学生呢? 小学缺老师则 找代课老师, 至于代课老师的教学经验、资历如何, 就没 有太多的要求了。

\section{3. 教学观念滞后}

进入新时代, 教学模式、教学观念已经更新换代了。 但是, 由于农村各方面条件的限制, 部分农村学校的教师 教育观念还是没法跟上时代发展的步伐。新形势下, 学校 提倡素质教育, 强调学生德、智、体、美、劳全面发展。 但是, 农村地区教学并没有提倡素质教育, 教育观念还未 发生改变。课堂上, 教师是主体, 以传授知识为主, 学生 是接受知识的机器。在这样的教学模式下培养出来的学 生, 学习的自主性不强, 仅会被动地接受知识, 没有自己 的独立思考能力。在语文教育中, 如果学生只是听教师讲 课, 没有自己的思考, 那么他们真正掌握的东西就没有多 少, 其思想也会僵化。例如, 遇到相同的问题, 若是换个 问法, 学生便不知所措。另外, 部分语文教师过于注重课 本知识, 教学中不会扩展, 仅单纯地带学生学课本。这样 的语文课是没有生机的, 也无法唤起学生学习语文的兴 趣。

在应试教育下, 不少教师过分关注学生的成绩, 分数 至上, 他们总是围绕着考试大纲进行教学, 怎么考就怎么 教。[4]如语文课本中的一些阅读课文, 不考便跳过不讲或 随便讲讲。这样, 学生真正掌握的只是考试的内容, 其余 则一概不知。这样培养出来的学生只是应试教育下的考试 工具, 几乎不具备创新能力。

\section{4. 教学语言方言化}

目前, 国家大力推广普通话, 以消除语言交际的障碍。 但是, 不少农村学校语言教学并没有跟上时代步伐, 课堂 上仍然实行“双语”教学, 存在教学语言方言化的问题。[2] 农村课堂的“双语”教学, 是指课堂教学中, 教师兼用普通 话和方言授课。为了推行普通话, 国家对教师要求很严格, 语文教师必须达到普通话水平二甲以上等级。尽管如此, 有些年龄较大的教师依然用方言或是普通话夹杂着方言 上课。即使有的教师以普通话上课, 但他们的普通话多是 不标准的。

在语文教育中, 字、音、词是最基本的。教师如果自 己的普通话尚且说不准, 何谈教好学生呢? 更不用说培养 学生的朗读能力, 带领学生体味语言的美了。在这方面, 笔者深有体会。笔者家乡的方言几乎是 $1 、 n 、 r$ 不分的, 翘 舌音只读平舌音。由于受方言的影响, 小学时老师的普通 话很不标准, 以致笔者直到现在要学好普通话都存在较大 的困难, 因为已经定了型的发音是很难改变的。为此, 笔 者要拿到普通话考证就要花费比别人更多的时间和精力。 由此可见, 教师在课堂中的教学语言是多么的重要啊! 教 师不仅要掌握标准的普通话, 还要认真揣摩如何教好学生 学习标准普通话, 正确运用字、音、词。

\section{5. 课标、教材更替调整中的问题}

新时期, 人们的教育观念发生了变化, 教材、课标也 有了新的改变。新教材、新课标更加注重学生学习的系统 性和连贯性, 各个年级之间的知识体系紧密地联系在一 起, 如果中间某个环节出现断层, 整体的教学效果就会受 到影响。例如, 教学过程中, 如果某个教师对新教材、新 课标的把握不到位, 接任的教师就很难去弥补这个空缺, 学生学习的连贯性就会中断, 其语文成绩就会下降。[9] 而在农村, 就有部分语文教师对新教材和新课标理解不 透, 或者说虽然理解了但是还不能很好地与实际教学结合 起来, 从而使其教学出现了超纲或低纲的问题。例如, 初 中文言文学习, 仅要求学生能看懂, 掌握一些简单的字、 句。但是, 没有搞清楚新课标的教师, 教学中就有可能要 求学生掌握文言文中一些较难的句式, 并且要求学生会使 用, 这就属于超纲了。而教学中出现的超纲或低纲问题, 必然会影响学生学习的连贯性和系统性, 影响整体的教学 效果。语言是人类最重要的交际工具, 语言是社会的, 语 言是随社会的发展而发展的。而在农村语文教育中, 由于 课标、教材调整没有跟上时代发展的要求, 学生不仅语言 水平要比城市的要低, 而且其成绩也难以得到提高。

\section{6. 教案抄袭沿用}

教案抄袭在农村语文教育中是常见的现象。有些教师 出于提高教学质量或其他原因, 备课时常常直接借用其他 教师的教案。[10]网络上、书刊上的教案, 质量的确是好, 但是这些教案大都是一些特级教师或优秀教师根据自己的 教学水平编写的。这些教师的教学基本功远远高于农村教 师, 农村教师就是使用了这些教案授课, 也难以达到理想 的课堂效果, 因为生吞活剥别人的教案是没什么用的。[8] 再者, 这些教师编写的教案所针对的学生群体, 其综合素 质整体上也高于农村学生, 用这些教案给农村学生上课, 他们不一定能够听得懂, 也不一定“消化”得了。所以, 别 人编写的教案并不一定适用于农村学校的教师, 也不一定 适用于农村学校的学生。如果盲目地抄袭别人的教案, 不 仅不利于学生语文水平的提高, 很多时候还会适得其反。

\section{3. 解决农村学校语文教育问题的对策}

\section{1. 增加农村学校教育经费的投入}

相对于城镇来说, 农村学校语文教学显得薄弱很多。 农村经济发展水平低、教育经费投入少是农村教育质量不 高的主要原因之一。因此, 为了提高农村教育水平, 政府 应该加大农村教育经费的投入, 为农村教学提供必要的教 学设施。比如, 为农村学校配备多媒体教学设施, 以摆脱 传统的一支粉笔、一块黑板的教学模式。多媒体教学设备 能够使农村语文课堂丰富多彩、生动有趣, 许多意境也能 通过多媒体展现出来, 这不仅有利于学生理解知识, 还有 利于培养学生的学习兴趣。[9,11,12]例如, 学习课文《观 潮》, 因为大部分内陆农村孩子没有看过外面的世界，对 海潮也是陌生的, 所以海潮的壮观景象仅靠课文中的文字 描述来想象是远远不够的。如果能通过多媒体展示图片、 
视频, 就可以将潮水的壮观景象生动形象地表现出来, 使 学生深刻地领悟文中所描绘的句子, 这就是多媒体存在的 意义。所以, 为农村学校配备多媒体设施是很有必要的。

另外，在加大农村教育经费投入的同时，一定要提高 农村教师的生活待遇, 这样才能提高教师工作的积极性, 留住优秀的年轻教师。许多优秀教师不愿留在农村, 其主 要原因就是农村学校福利待遇没有城市的好。只有提高了 农村教师的工资福利待遇, 优秀教师才愿意留下来。如果 农村有大批的优秀教师, 一定会提高农村的教学质量, 进 而从根本上扭转农村教育落后的局面。同时, 国家应积极 鼓励大学生回乡任教, 以回乡任教为荣, 并积极倡导城市 教师到农村任教, 这样农村教师水平就会有一个大的提高。

\section{2. 更新教学观念, 树立科学理念}

\subsection{1. 教师要摒弃“分数至上”的教学观念}

部分教师的教学观念滞后, 是农村学校语文教育质量 不高的原因之一。现代教育提倡素质教育, 要求学生全面 发展。但是, 农村学校并没有贯彻素质教育这一方针。不 少教师仍是分数至上, 其教学内容是按考试大纲考什么就 教什么。例如, 农村学校评选“三好学生”, 实际上就是“一 好学生”一学习成绩好。这样的教育观, 只会让学生沦 为应试教育的考试工具, 并不符合当今社会培养人才的需 要。要想提高农村学校语文教育的质量, 摒弃“分数至上” 的教学观念很重要。在语文课堂上, 教师要教给学生的不 应该只是考试大纲所规定的内容, 还应该注重增长学生的 见识, 扩大学生的视野, 发展学生的思维, 提高学生的整 体语文素质, 从而增强学生解决问题的实际能力。

\subsection{2. 教师要树立以学生为主体的教学理念}

在农村学校语文教学中, 课堂仍然是以教师为主, 学 生只是被动的接受者。所谓教学, 顾名思义就是指教与学 的双向互动, 而非教师“一枝独秀”。在教学活动中, 仅以 教师为主体, 而学生只是被动的接受者, 这是本末倒置的 做法, 因为教师的一切教学活动都是为了学生, 学生才是 主体。[5]教学中以学生为中心, 根据学生的实际情况实施 教学, 培养学生自主学习的能力, 让学生成为课堂的主体, 这才是学生掌握知识、发展能力的正确途径。城镇课堂教 学, 学生是学习的主人, 教师实施启发式教学。

那么, 农村学校语文教学应该怎样让学生成为课堂的 主体呢? 首先, 讲课前应要求学生预习课文, 并思考课文 后的练习题。这样, 学生对课文就有了一定的理解, 有了 自己的看法和思考, 他们就不会被动地接受知识。其次, 在语文教育中, 教师要创设一定的问题情境, 让学生进行 思考, 激发他们的学习兴趣。学生有了兴趣, 才会自觉地 参与课堂, 成为课堂的主体。最后, 课堂教学中, 要彻底 改变教师唱独角戏的局面, 真正让学生参与到课堂中来, 要与学生一起完成课文的教学任务。[7]

\subsection{3. 教师要养成“终身学习”的自觉意识}

“活到老, 学到老”, 这是人们常说的筬言, 但是却很 少有人真正去实施。这种现象在农村学校尤为严重, 当然 这与农村地理位置偏僻, 相对闭塞, 难以获取信息有关。
不少农村教师对教育的认知还停留在以前的老观念上, 殊 不知时代变化了, 教育观念也要随之改变, 否则培养出来 的学生也就无法成为社会所需要的人才。所以, 教学观念 滞后的教师必须改变自己的教育观念, 养成“终身学习”的 自觉意识。教师要通过不断地学习和实践, 以先进的教育 理念去指导“教书育人”这一神圣事业。[8]另外, 农村教师 相对于城市教师来说所受的教育要少, 更需要通过不断地 学习来提升自己。教师只有有了足够的知识储备, 才能满 足学生的知识渴求。教师应该成为“自来水”的源泉, 永不 停流, 永不枯竭, 所以教师必须树立终身学习的意识。

\section{3. 进行业务技术培训, 不断提高教师的教学技能}

\subsection{1. 必须进行普通话培训}

语言不仅是交际工具, 还是思维载体。要学好语文, 语言是基础。课堂教学中, 语言首先就体现在教师的普通 话水平上。然而, 许多农村教师的普通话是不准的。语文 课堂对普通话的要求尤为严格, 教师必须起到表率作用, 说好普通话。所以, 对普通话不准的农村教师进行培训显 得尤为重要。教育职能部门、学校应该重视农村教师普通 话的培训工作, 不断提高他们的普通话水平。只有这样, 教师才能为学生做好示范。首先, 要有计划地培训教师, 促使他们重视普通话的训练。其次, 要定期对教师进行普 通话水平检测, 以获取普通话等级证书作为职称评聘的一 个必要条件。最后, 课堂中教师必须以普通话授课, 否则 就不得在教学岗位上任职。

\subsection{2. 必须学会使用多媒体教学}

不善使用多媒体也是影响农村语文教育效果的原因 之一。因此, 很有必要对教师进行多媒体教学技术方面的 培训。多媒体教学技术培训应该多管齐下, 一是教育主管 部门组织培训, 二是学校安排学习课程。让多媒体在教学 中真正发挥作用, 而不能仅成为少数教师的“专利”, 或者 仅将之作为一个装饰门面的摆设。

\section{4. 加强城乡教师的沟通与交流}

农村教师整体素质不如城市的高, 究其原因主要有以 下几方面造成的: 首先, 就整体而言, 农村教师所受教育 的程度低于城市, 不容置疑其自身能力也就略逊于城市教 师; 其次, 城乡培训学习的机会不同, 城市教师培训学习 的机会多, 成长也就更快; 而农村则不然, 由于农村经济 条件不允许, 自然也就没有优越条件为教师提供更多的培 训学习机会。有些农村地区虽然组织了一些教育培训, 但 形式化过于严重, 其效果也不佳。教师培训未能有效地进 行, 就使许多农村教师的自身素质、教育教学理念与新课 程标准存有较大的偏差。[13]最后, 城乡教师所处的环境 不同, 其思想观念也有所不同。城镇教师更易接触到新事 物、新观念, 视野开阔, 见多识广, 接受新思想也更快。 而农村相对比较闭塞, 与社会接轨的程度没有城市高, 大 部分农村教师所接触到的新事物、新思想没有城市教师的 多, 因而有新的教学思想出现的时候, 接受的过程就比较 慢。因此, 加强农村教师与与城市优秀教师的交流是十分 重要的。[3] 
那么, 应如何加强城乡教师的沟通和交流呢? 第一, 建立双方有效的互动机制, 定期召开城乡教师的交流座谈 会。座谈会上, 双方可以就教学体验、教学方法以及教学 经验等进行交流。第二, 组织语文观摩课, 并适时举行一 些教学竞赛活动, 让农村教师领悟城镇优秀教师的教学艺 术, 取其长补已短, 以提高自身的教学效果。第三, 采取 结对子的方式, 实行一对一传、帮、带的措施, 让农村教 师特别是青年教师尽快成长起来。当然, 除了这些方式之 外, 在现代科技发达的时代, 还可以利用现有的先进技术 如网络, 为城乡教师交流提供便利。利用网络沟通与交流, 这不仅省去很多时间和花费，还可以让双方有更多的交流 机会。

\section{5. 杜绝抄袭教案, 精心写出适合农村学生的教案}

抄袭教案是农村学校语文教育中存在的普遍现象, 这 严重地影响了语文教育质量。因此, 必须杜绝教案抄袭这 种现象, 精心写出适合农村学生实际水平的教案。要写好 适合农村学生的教案, 就必须要联系农村学生的实际情 况。农村大部分学生, 阅读量少, 知识积累不多, 理解能 力不强。教师在制定教案时就必须考虑这些实际情况, 降 低教案的难度, 以掌握阅读理解、基础知识为主要内容和 学习目标。另外, 教案的编写也要考虑学生的实际生活情 况。农村经济较为落后, 大部分家庭的经济负担较重, 很 多农村孩子的父母外出打工, 于是就有不少留守儿童, 只 能由家里老人负责监管。多数留守儿童缺乏有效的家庭教 育, 学习热情不高, 自觉性不强, 学习成绩也不理想。[6] 所以, 农村学校语文教育, 教师一定要注意培养学生的自 信心, 多鼓励他们。[4]当他们进步时, 要及时表扬他们, 要让他们深信自己是可以成功的, 以增强他们的自尊心和 自信心。再者, 即使在家务农的父母, 与孩子的交流也较 少。究其原因: 一是不知道怎么与孩子进行有效交流; 二 是忙于农活而没时间与孩子进行交流。所以，农村语文教 师一定要注重孩子的情感教育。课堂中, 教师可以从课文 的情感引入生活的情感, 与学生加强情感交流, 要多了解 他们, 关爱他们, 让他们懂得父母是爱他们的, 并鼓励他 们多与父母沟通。

此外, 教案的内容还得依据新课标的要求来确定。新 课标不仅仅关乎教学, 也关乎着国家培养什么人的问题。 农村教师不按新课标要求授课, 培养出来的学生就难以符 合国家的要求。所以, 教师把握新课标是十分重要的。新 课标要求语文教师在教学中要做到: 第一, 要注重语文知 识的学习, 也要注意学习方式的改善。教师要相信学生, 要为学生创造自主学习的环境, 培养他们自主学习的能 力。学生学会自主学习, 有独立思考的能力, 才符合国家 推行的素质教育标准。第二, 在教学过程中, 教师要注意 学生的个性发展。所谓“发展”是指学生的全面发展, 即各 个方面的综合发展。所以, 在语文课堂学习中, 教师除了 要对学生进行智力培养外, 还要注重德育, 使之弘扬传统 美德, 形成正确的价值观。第三, 要培养学生的协作精神。 新课程改革的一个亮点就是小组合作, 这可以培养学生的 团结协作精神。在语文教育中, 教师要多组织学生小组讨
论各类问题, 在讨论中体会合作精神。[14]备课时, 教师 应按照新课标的要求去写好教案, 把握其教学内容。

\section{4. 结语}

从总体上看, 经济发展水平低是农村语文教育质量不 高的根本原因, 而经济原因就直接或间接地导致了农村学 校教学设施的贵乏, 加之师资力量的薄弱, 教育观念的滞 后以及教学语言方言化等问题, 这就使农村教育问题积重 难返。针对农村学校语文教育中存在的问题, 在此提出一 些建议: 一是国家应增加对农村教育的经济投入。二是教 师要紧跟上时代发展步伐, 更新教学观念, 以科学的理论 方法指导教学工作, 并对其进行业务培训, 加强城乡优秀 教师的交流与合作。最后, 杜绝教案抄袭现象, 写出适合 农村学生的优质教案。

\section{参考文献}

[1] 张静.浅析农村教育现状[J].农民致富之友,2015(12)。

[2] 李云洲. 提高农村小学语文教育教学的有效性的对策分析 [J].课程教育研究,2017(12)。

[3] 李娜.浅谈我国农村教育现状及对策[J].农业科技与信 息,2020(05)。

[4] 刘建尔.新课改视野下农村语文教育的困惑与策略初探 [J]. 西北成人教育学报,2012(01)。

[5] 陈强.素质教育背景下农村语文教育策略研究[J].成才之 路,2016(04)。

[6] 李松.新中国成立70年我国农村教育:经验、问题与对策[J]. 河北师范大学学报(教科版),2019(04)。

[7] 李爱丰.农村语文教学中培养学生问题意识的策略[J].小学 教学参考, 2011 (30)。

[8] 李金云,高玉霞.西北农村初中语文教师教科书助学系统使 用现状的调查研究[J].当代教育与文化,2017(04)。

[9] 许外香. 新课改对农村初中语文教育的影响及优化建议[J]. 科学咨询(教育科研),2019(01)。

[10] 方祥珍.农村语文课堂教学现状与对策分析 [J].小学教学参 考,2012(21)。

[11] 刘爱华.浅议新课改背景下信息技术在农村小学语文教育 中的应用[J].亚太教育,2016(13)。

[12] 张朋.浅析多媒体在农村语文课堂教学中的应用[J].中国新 技术新产品,2011(24)。

[13] 晏进轩.当前农村初中语文课堂现状分析与改革策略[J].新 课程研究(上旬刊),2011(11)。

[14] 徐燕.农村小学阅读教学的现状和应对策略 [J]. 小学教学参 考,2019(01)。 